\title{
The Impact of Leadership Style on Employee Performance in Higher Education Institution in Somalia: A Case of Mogadishu City
}

\begin{abstract}
Abdifatah Omar Ga'al*
Somalia

*Corresponding Author: Abdifatah Omar Ga'al, Somalia

Abstract: The emphasis is on how Somali higher institutions can get effective leadership style to achieve set goals. There are vacuum of true conscious leaders, whether in politics, religion, organization, business, education, sports or institutions. There is desperate need of competent, principle, sensitive, compassionate and conscious leaders. In this the research emphasis will be placed on the need to know what makes a leader and what makes a follower. Qualities that distinguish leaders from followers.The various styles of leadership and how goals can be set and achieved. This research is about the missing link in leadership styles, with impact on the performance of the follower or employee of an organization with focus on Somali higher institutions. Despite these variations, there are at least three important implications of these definitions. Firstly, leadership is a process engaged in by certain individual (leaders). It is an ongoing activity in an organization. Secondly, it involves other people in form of subordinates who by their willingness are influenced by the leader. Therefore, the subordinates formalize the leader's authority by making leadership process possible. Thirdly, the aim of leadership is accomplishment of goal and objectives, a pointer that the leaders attempt at influencing the subordinate are directional and therefore aim at level of achievement. The Impact of leadership style on Employee performance in Mogadishu Higher Educational This research analyzes the available literature of leadership styles and effect on different components of Quality of work life. The findings indicated that Laissez-faire leadership style would have the most effect $(r=.975)$, followed by transactional leadership at ( $r=.969)$, and transformational leadership at $(r=.965)$.
\end{abstract}

\section{INTRODUCTION}

Leadership is simply the art of influencing people so that they will strive willingly towards the achievement of goals (Igbaekemen, 2014).Leadership is one of the most pressing issues and one of the least understood concepts in the corporate world. On the other hand,Bass,Avolio,Jung\&Berson (2014) contends that the history of leadership encompasses through several paradigm shifts and voluminous body of knowledge.

As a universal activity, leadership is fundamental for effective organizational and social functioning. The very nature of leadership is its influencing process and its resultant outcomes. Such process is determined by the leaders and followers characteristics, dispositions, behavior perceptions, attributions and the context wherein the process of influencing occurs. The moral purpose of leadership is to create an empowered follower that leads to moral outcomes that are achieved through moral means (Hersey \& Blanchard, 1984).

. The impact of leadership style is vitally important at all levels of management within the organizations.

Leadership is the moral and intellectual ability to visualize and work for what is best for the company and its employees (Mullins, 2006).

Leadership has is not confined to businesses alone, but is significant in all areas and institutions. Unus and Beacon (2007) noticed that more than one thousand four hundred years ago, the Quran, the Divine words that is revealed to Prophet Muhammad (peace and Blessings be upon Him), demonstrated some good examples and styles of leadership. A good example is including Prophet Suleiman who provided effective leadership that has saw the growth of Islam across the world. 
Employee performance could improve organizational performance as well. Deadrick and Gardner's (1997) defined employee performance as the record of outcomes achieved, for each job function, during a specified period of time. On the other hand, Darden and Babin (1994), explains that if viewed in this way, performance is represented as a distribution of outcomes achieved, and performance could be measured by using a variety of parameters which describe an employee's paten of performance over time.

The organizational focus of the leader has evolved over time with significant improvement being realized. Early organizations have authoritarian leaders who believed employees were intrinsically lazy and transitioned into way to make work environments more conducive to increase productivity rates. Today, organizations are Transforming into places where people are empowered, encouraged, and supported in their personal and professional growth throughout their careers (Kouzes and Posner, 2014).

Leadership has changed over time, it has influenced and shaped the development, progressing of and application of traditional leadership theories (Stone \& Patterson, 2005) On the other hand Albritton (2015) recognized that leadership, especially in Africa, is difficult and management systems appear currently to be mainly results and control oriented other than process oriented although there are variation from one country to another. While management in is more control oriented in Democratic Republic of Congo and Mozambique in Rwanda, Burkina Faso and Botswana the management is more people or normative oriented, Mazrui (2007) stresses that for Africa to meet its new millennium demands exceptional leadership, needs to be considered.

As the world experiences varied changes due to globalization and the emergence of a new style of leadership, it is only critical that Africa reviews its leadership approaches if it is going to be competitive. On the other hand, while there are many challenges, particularly of political, culture, poverty, illiteracy and disunity in the continents, the coming together of Africans leaders in Mombasa in 2004 and earlier in Gaborone to maximize and affirm the potential for positive leadership in the continent, is a remarkable move towards solving issues that are related to leadership in Africa (Rotberg, 2004)

Effective leadership is crucial in today's competitive business environment. As organizations develop different strategies to improve performance, Bass (2014) contends that very little is going to be realized if these strategies are not focused on effective leadership that can influence employees' performance. Employees are the most important assets in organizations, which without, the goals and objectives may not be attained. Several studies have been conducted on the roles that good leaders can play in achieving increase employee job performance. A good leadership may play a mediating role in the relationship between organizational culture and employee outcomes and an atmosphere for good leadership to flourish; which will ultimately leads to increased employees job performance (Toor\&Ofori, , 2009).

A number of recent studies such as Rasool, et al. (2015);Pradeep and Prabhu (2011);Aboshaqah et al, (2015); Ipas (2012);Kahinde and Bajo (2014) ; Tsigu and Rao , 2015) ; Gimuguni et al , (2014) ; and Raja and (Palanichamy , 2015) among other examined the impact of leadership styles on employeese performance and established a relationship between leadership and employees performance.

While Tsigu and Rao (2004) explained the variation is employee performance better than transaction leadership Style, Gimuguni et al (2007) report significantly positive relationship between autocratic, laissez-faire and democratic and performance. Anyango (2015) stressed that the university must become a primary tool for Africa's development in the new century. Bass (2015) acknowledges that universities that can help develop African expertise; they can enhance the analysis of African problems; strengthen domestic institutions; serve as a model environment for the practice of good governance, conflict resolution and respect for human rights, and enable African academics to play an active part in the global community of scholars.

After long years of instability, effective leadership in Somalia is indispensible not only in the political circle but also in institutions, businesses and organizations in different areas. Additionally, there are no proper researches that have been done in the country and therefore there is no evidence of exiting literature or relevant studies on the impact of leadership on employee performance. Therefore, this 
study intends to examine the impact of leadership on employee performance in institutions of higher learning.

This study acknowledges that leadership style that refers to a leader's characteristic behaviors when directing, motivating, guiding, and managing groups of people can have a great significance influence on the employees' performance. On the other hand, great leaders can inspire political movements and social change and can also motivate others to perform, create, and innovate. The leader includes one or more employees in the decision making process, but it is important to note that the leader normally maintains the final decision making authority.

\section{LITERATURE REVIEW}

Leadership is the process of persuasion by which an individual induces a group to pursue objectives held by the leaders and his followers. Leadership is a social function necessary for the achievement of collective objectives. As stated byPielstick (2015). The transforming leader: A meta-ethnographic analysis leadership is not just a position in a hierarchy or a chain of commands, but involves actions of the leader. This approach to leadership sees leadership as a process of mutual interaction between leader and followers the process of leadership may be thought of consisting of a number of different functions such an inspiring subordinates, forming and reaching collective goals, and preserving groups cohesion, each of these functions can be accomplished by many different leadership (Nirenberg, 2001).

As previously suggested, there is a significant body of literature that implies the relationship between leadership style and employees performance.

The various leadership styles have different impacts on the way employees perform in their organization. In both private and public organizations, the component of leadership is the one with the most dynamic effects during individual and organizational interaction. In other words, the ability of management to execute planned objectives depends on leadership capability. Mehra (2016) explain that the excellent leader not only inspires subordinates' potential to enhance efficiency, but also meets their requirements in the process of achieving organizational goals through employee's performance. This literature describes leadership styles and employee performance from a crowd of angles and views. Many articles also repeat the same topics and findings and the author chose to include just to show that the findings are similar but from a wide range of domains. In many researches in the literature it was determined that there was a strong relationship between leadership styles and employee performance (Lo et al., 2009; Lo et al., 2010; Avolio et al., 2004; Bučiūnienė\&Škudienè, 2008; Lok\& Crawford, 1999; Awan\&Mahmood, 2009; Ponnu\& Tennakoon,2009).

Operationalization of the study Variables

\begin{tabular}{|l|l|l|}
\hline Variable Type & Variable & Operationalization of the Variable \\
\hline & Laissez-faire leadership & $\begin{array}{l}\text { Hands-off with minimal direction expected to } \\
\text { solve problems on their own; and complete } \\
\text { freedom for junior staff to make decisions. }\end{array}$ \\
\cline { 2 - 3 } & Transactional Leadership & $\begin{array}{l}\text { Rewards and Incentives; Punishments on } \\
\text { performance results; and Motivates and stimulates. }\end{array}$ \\
\cline { 2 - 4 } & Transformation Leadership & $\begin{array}{l}\text { A Leader Influence the Employees to achieve the } \\
\text { required Change; Responsive to Situation; and is } \\
\text { focused on organization objectives. }\end{array}$ \\
\hline Dependent Variable & $\begin{array}{l}\text { Employee performance in } \\
\text { higher education institution in } \\
\text { Mogadishu }\end{array}$ & $\begin{array}{l}\text { Timely completion of task, Meeting of } \\
\text { performance targets. }\end{array}$ \\
\hline
\end{tabular}

\section{RESEARCH METHODS}

This study is a survey that will involve the impact of leadership style on employee performance in higher education institutions in Somalia The study will therefore focus on specifically those higher education institutions that are within the geographical boundaries of Mogadishu. 


\section{Target Population sampling for the study}

According to Panneerselvam (2004) a total population is the entire spectrum of a system or process of interest. This description is in tandem with that of Johnston and VanderStoep (2009) which defines a population as the universe of people to which the study can be generalized. According to Mugenda and Mugenda (2003), population is a complete set of individuals, cases or objects with common observable characteristics. The population of a study includes all the elements that stand a chance of being included in the study. In the current study, the population will include all the higher education institutions in Mogadishu. There are approximately 80 higher education institutions in Mogadishu that are operating in Mogadishu and the researcher will target the university administrations, academic departments, admission departments, faculty deans, lecturers; 2 from each of the 80 making a target population of 160 employees.

\section{Sample Size Determination}

The study selected a sample based on probability sampling which means that the units are selected randomly. The current researcher used random sampling. According to Krejcie, Robert, Morgan \&Daryle (1970) in appendix ii, the sample size were 100 Lecturers respondents who were randomly drawn from the higher education institutions in Mogadishu.

The study sample was determined through Yamane (1967) simplified formula which was supported by Coopers (2006) for sample proportion;

$$
\mathrm{n}=\underset{1+\mathrm{N}(.05)}{\mathrm{N} 2}
$$

$\mathrm{N}=$ (There were 160 lecturers ( 2 from each of the 80 Universities) purposively picked for the study.

Therefore; $160 / 1+160(0.0025)=100$

Population Sample $=100$ Lecturers

\section{Sampling procedure}

Simple random sampling was used to draw 100 respondents from the higher education institutions in Mogadishu, Somalia. Since not all of the higher education institutions in Mogadishu are operational, purposive sampling method was also applied to select the qualified respondents from each of higher education institutions. Where the lectures were not there from a particular institution others were purposively selected to complete the sample size since certain institutions of higher learning might not be in operation or are totally new.

\section{Data Collection}

\section{Types of data}

This study used primary data as the main source of information. Data refers to all the information to be collected by the researcher to complete the study; these data include facts and figures relating to a particular activity under study. Primary data is best collected from interaction with the respondents through the aid of hired research assistants (Mugenda\&Mugenda, 2003); this involved administration of questionnaires to various lecturers of the higher education institutions involved and interviewed guide for the vice chancellors.

\section{Research instruments}

The study was mainly be based on primary data that was collected through questionnaire for the lecturers and interview guides for the vice chancellors. The primary data that was collected in the study was based on the impact of leadership style and employee performance in Mogadishu higher Educational Institutions.

\section{Questionnaires}

The researcher developed a self-administered questionnaire as a means of data collection from respondents. The structured questionnaire was in English Language and was developed in a five point Likert scale format. The instrument was divided into five sections. One section contained the 
The Impact of Leadership Style on Employee Performance in Higher Education Institution in Somalia: A Case of Mogadishu City

demographic information while the other four contained questions relating to the objective of the study and study variables.

\section{Key Informant Interview}

On the other hand qualitative data that was collected using Key Informant Interview schedules that targeted 10 leading higher education vice chancellors. The in-depth interviews for Key Informant collected views from higher education institutions vice chancellors to supplement information obtained from the lecturers.

Table3.1. Validity and reliability test of the research instruments

\begin{tabular}{|c|c|c|c|c|}
\hline & $\begin{array}{l}\text { Scale } \\
\text { Mean } \\
\text { if Item } \\
\text { Delete } \\
\mathrm{d}\end{array}$ & $\begin{array}{c}\text { Scale } \\
\text { Variance } \\
\text { if Item } \\
\text { Deleted }\end{array}$ & $\begin{array}{l}\text { Corrected } \\
\text { Item-Total } \\
\text { Correlation }\end{array}$ & $\begin{array}{l}\text { Cronbach'sAlpha } \\
\text { if Item } \\
\text { Deleted }\end{array}$ \\
\hline Gender & 92.9404 & 1073.681 & .690 & .995 \\
\hline Education Level & 92.1529 & 1067.471 & .723 & .995 \\
\hline Marital Status & 92.5904 & 1066.926 & .850 & .995 \\
\hline Work Experience & 91.4154 & 1026.045 & .954 & .994 \\
\hline My leader makes the employees feel good to be around him. & 90.7154 & 1000.240 & .966 & .994 \\
\hline The employees in our organization have complete loyalty in & 90.7904 & 1012.915 & .969 & .994 \\
\hline My leader provided interesting image of what we can do & 91.0779 & 1018.411 & .963 & .994 \\
\hline $\begin{array}{l}\text { My leader is satisfied only when employees meet agreed-upon } \\
\text { Standards. }\end{array}$ & 91.0529 & 1028.066 & .945 & .994 \\
\hline My leadership does not try to change if everything is working & 90.6654 & 1023.418 & .947 & .994 \\
\hline My leader gives us the standards of the work to be done & 90.8154 & 1003.015 & .973 & .994 \\
\hline My leader considers the moral and ethical consequences of decisions & 90.9904 & 1028.115 & .938 & .994 \\
\hline My leader does not ask more than what is absolutely essential. & 90.9029 & 1021.494 & .968 & .994 \\
\hline $\begin{array}{l}\text { The appealing ability of the supervisor can make a payment to the } \\
\text { effectiveness of the job done }\end{array}$ & 90.9029 & 1028.642 & .945 & .994 \\
\hline $\begin{array}{l}\text { The employees are satisfied when the leader goes beyond self-interest } \\
\text { for the good of the group }\end{array}$ & 90.7154 & 1020.940 & .962 & .994 \\
\hline $\begin{array}{l}\text { The quality of the tasks is improved when the leader emphasizes } \\
\text { employee needs. }\end{array}$ & 90.4779 & 1004.728 & .946 & .995 \\
\hline $\begin{array}{l}\text { When the leader focuses only on the mistakes and interact procedures } \\
\text { are not followed, the performance decrease }\end{array}$ & 90.9904 & 1012.635 & .971 & .994 \\
\hline $\begin{array}{l}\text { When leader focuses punishment, employees achieve only the minimal } \\
\text { expectation to avoid penalties. }\end{array}$ & 90.9404 & 1027.867 & .942 & .994 \\
\hline $\begin{array}{l}\text { A free-run management style may cause unlimited time for task } \\
\text { activities. }\end{array}$ & 91.0779 & 1024.874 & .947 & .994 \\
\hline Little or no direction from the leader makes employees job quality poor. & 90.4404 & 1020.392 & .961 & .994 \\
\hline Leaders_set_up_goals_to_be_achieved_by_the_employees & 91.0154 & 1008.396 & .977 & .994 \\
\hline There_are_task_force_created_by_leaders_to_achieve_various_tasks & 91.2154 & 1012.507 & .965 & .994 \\
\hline The leaders sets goals to be achieved by the employees & 90.9904 & 1017.101 & .970 & .994 \\
\hline $\begin{array}{l}\text { There are task forces and groups created by leaders to achieve various } \\
\text { tasks and activities }\end{array}$ & 91.0904 & 1004.955 & .958 & .994 \\
\hline The leaders assigns duties that are led by certain employees & 91.0279 & 1000.345 & .937 & .995 \\
\hline All the tasks and activities are evaluated after a certain duration & 90.8779 & 1041.955 & .901 & .995 \\
\hline $\begin{array}{l}\text { The leadership style adapted by the management contribute to the } \\
\text { employees achievement of various tasks }\end{array}$ & 90.8529 & 1015.619 & .939 & .994 \\
\hline
\end{tabular}

Data analysis

The data that was collected were in both figures and statements or both quantitative and qualitative in nature. In order for the researcher to conduct analysis on the collected data, data sorting was necessary to ensure completeness of the data. Data coding was also done especially for the qualitative data. This was necessary in order to give the qualitative data a quantitative approach in analyzing it.

In order to establish the effect of microfinance services on financial performance, responses obtained from the respondents will be aggregated and correlated against the return on assets of the small scale enterprises. Pearson's correlation coefficient and multiple regression was used to determine the nature and the extent of the relationship between the independent variables (Leissez-faire Leadership,Transactional Leadership Style and Transformational Leadership Style) and dependent 
variable(Employee performance in higher education institution in Mogadish). The data was analyzed using mean scores, and f- test then be presented in the form of frequency tables, charts and graphs where necessary. A regression model was applied to determine the relationship between the variables of the study.

Pearson correlation analysis and multiple regression model were used, which will take the form of:

$\mathrm{Y}=\beta 0+\beta 1 \mathrm{X} 1+\beta 2 \mathrm{X} 2+\beta 3 \mathrm{X} 3+\dot{\varepsilon}$

Where: $\mathrm{Y}=$ Employee performance in higher education institution in Mogadishu

$\mathrm{X} 1, \mathrm{X} 2$, and $\mathrm{X} 3=$ Independent Variables

$\mathrm{X} 1=$ Transformational Leadership Style

$\mathrm{X} 2=$ Transactional Leadership Style

X3= Leissez-faire Leadership

$\dot{\varepsilon} .=$ Error Term

B1 ... B3= Regression co-efficient of five variables

Thematic analysis was used to analyze the qualitative data according to the objectives of the study from the interview guides. Triangulation was done for both the results from questionnaires and interviewed guide.

\section{DISCUSSION OF FINDINGS}

The findings of the study indicated that laissez -fair leadership was the most prevalent of all the leadership styles adapted by the institution of higher learning in Somalia. The second most prevalent of all the leadership styles adapted by the institution of higher learning in Somalia was transactional leadership style then democratic leadership style. The lowest leadership style adapted by the learning institutions in Somalia was autocratic leadership style.

The study had sought to establish the effects of Transactional Leadership on employee performance in higher education institutions, results indicated that leadership not trying to change if everything is working would have the most influence on employees' performance among all the transactional leadership factors, followed by leader making the employees feel good to be around them. The factors with the lowest influence on employee's performance among transactional leadership factors were leader providing interesting image of what they can do.

On transformational leadership factors, the findings indicated that employees are satisfied when the leader goes beyond self-interest for the good of the grouphad the most influence on employees performance in institutions of higher learning among all the transformation leadership style factors, followed by their leader giving them the standards of the work to be done. The factor with the lowest influence on employee's performance under transformation leadership style was leader considers the moral and ethical consequences of decisions.

When the study sought to establish, the effects of Laissez Faire Leadership style on the employees performance in institutions of higher learning, the findings of the study also indicated that little or no direction from the leader makes employees job quality poor among all the Laissez Faire Leadership style factors, followed by the quality of the tasks is improved when the leader emphasizes employee needs. The factor with the lowest was a free-run management style may cause unlimited time for task activities.

On the extent to which leadership styles adapted by the institutions would influence employees performance, the findings indicated that Laissez-faire leadership style would have the most effect $(r=.975)$, followed by transactional leadership at $(r=.969)$, and transformational leadership at $(r=.965)$.This means that if the learning institutions improved on their leadership style in order of Laissez-faire leadership style, transactional leadership and then transformational leadership then they would achieve high levels of employees performance.

On the other hand the Adjusted R Squared of .950 indicated that Laissez Faire Leadership style, in exclusion of other variables, would explains the changes in the employee performance in higher 
education institution in Mogadishu by 95\%, transactional leadership style and transactional leadership style each in exclusion of other variables, would explains the changes in the employee performance in higher education institution in Mogadishu by 93.1. This means that if measures separately, the application of Laissez Faire Leadership style would responsible for most of the changes in the employee performance in higher education institution in Mogadishu.

The findings of the study also indicated that combined Leadership Style factors Transactional, Transformational and Leissez-faire Leadership in exclusion of constant variable, explains the changes in the employee performance in higher education institution in Mogadishu by $95 \%$. This means that they leadership styles are crucial factors in achieving high levels of employees' performance in institutions of higher learning.

\section{CONCLUSION}

This study investigated the Impact of leadership style on employee performance in Mogadishu. Results from both the questionnaires and interviewees established that there is a significance relationship between leadership style and employee performance in institutions of higher learning in Mogadishu. The study established that there is need for Universities and institutions of higher learning to develop effective leadership that can influence their employees to perform better and that can ensure that they are able to meet their goals and objectives.

This study also found that the leadership have central role in employees performance in institutions of higher learning in Mogadishu. This means a strong leadership increases employees' level of performance and creativity. A very high performing workforce ensures high levels of institutional performance.

Therefore, it can be concluded that leaders are more effective when they use the appropriate leadership style.

\section{REFERENCES}

[1] Abraham, S. E., Karns, L. A., Shaw, K., \& Mena, M. A. (2001).Managerial competencies and the managerial performance appraisal process. The Journal of Management Development, 20(9/10), 842-853.

[2] Amos, T. L., Ristow, A., \&Ristow, L. (2004).Human Resource Management (2nd Edition). Lansdowne: Juta and Co Ltd.

[3] Anderson, T. D., Frod, R., \& Hamilton, M. (1998).Transforming Leadership: equipping yourself and coaching others to build leadership organizations (6th Edition). London: St. Lucie Press.

[4] Armstrong, M., \& Baron, A. (1998).Performance Management - The new Realities. London: IPD.

[5] Adler, R. W. \& Reid, J., 2008. The Effects Of Leadership Styles And Budget Participation On Job Satisfaction And Job Performance,Asia-Pacific Management Accounting Journal, 3(1), 21-46.

[6] Akor, P. U., 2014. Influence of Autocratic Leadership Style on the Job Performance of Academic Librarians in Benue State.Journal of Educational and Social Research, 4(7), 148-152.

[7] Akram, M., Alam, H. M., Ali, L. \& Mughal, M. M., 2012. How Leadership Behaviors Affect Organizational Performance in Pakistan,Journal of Economics and Behavioral Studies, 4(6), 354-363.

[8] Alghazo, A. M. \& Al-Anazi, M., (2016) The Impact of Leadership Style on Employee's Motivation,International Journal of Economics and Business Administration, 2(5), pp. 37-44.

[9] Ali, A., 2012. Leadership and its Influence in Organizations - A Review of Intellections, International Journal of Learning \& Development, 2(6), 73-85.

[10] Amanchukwu, R. N., Stanley, G. J. \&Ololube, N. P., (2015). A Review of Leadership Theories, Principles and Styles and Their Relevance to Educational Management,Management, 5(1), 6-14.

[11] Anbazhagan, S. \&Kotur, B. R., 2014. Worker Productivity, Leadership Style Relationship. IOSR Journal of Business and Management (IOSR-JBM), 16(8),62-70.

[12] Ansari, M. A., Ahmad, Z. A. \&Aafaqi, R., 2004. Organizational Leadership in the Malaysian Context.Leading in High Growth Asia, pp. 109-138.

[13] Arham, A. F., 2014. Leadership And Performance: The Case Of Malaysian Smes In The Services Sector,International Journal of Asian Social Science, 4(3), pp. 343355.

[14] Armstrong, M., Taylor \& S. (2014).Armstrong's handbook of human resource management practice.Kogan Page Publishers. 
The Impact of Leadership Style on Employee Performance in Higher Education Institution in Somalia: A Case of Mogadishu City

[15] Babatunde, O., 2015. The Impact of Leadership Style on Employee's Performance in an Organization. IISTE, 5(1), 193-206.

[16] Benjamin, O. A., 2015. Impact Of Organizational Culture And Leadership Style On Quality Of Work-Life Among Employees In Nigeria,African Journal For The Psychological Study Of Social Issues , 18(1), pp. 109121.

[17] Bhatti, N. et al., 2012 .The Impact of Autocratic and Democratic Leadership Style.International Business Research, 5(2), pp. 192-201.

[18] Bass, B. M., Avolio, B. J., \&Goodheim, L. (1987).Biography and the Assessment of Transformational Leadership at a World Class Level.Journal of Management .

[19] Brownell, J. (2008). Leading on land and sea: Competencies and context, International Journal of Hospitality Management, 27, 137-150.

[20] Corvellec, H.(1995). Stories of Achievement: Narrative Features of Organizational Performance. Sweden: Lund University Press.

[21] DiStefano, J. J., \&Maznevski, M. L. (2000). Creating value with diverse teams in global management,Organizational Dynamics, 29, 45-63.

[22] Hook, M. F. (1999). Introducing Human Resource Management,. London: Longman.

[23] Kaempf, G. L., Wolf, S., \& Miller, T. E. (1993). Decision making in the Aegis combat information centre. Proceedings of the Human Factors and Ergonomics Society 37th Annual Meeting (pp. 1107-1111). Santa Monica, CA: Human Factors and Ergonomics Society.

[24] Kaplan, R. S., \& Norton, D. P. (1996).The Balance Scorecard, The Harvard Business School Press.

[25] Martiz, D. (1995). Leadership and Mobilizing Potential Human Resource Management,International Journal of Global Business, 10(1), 8-16.

[26] Maxwell, J. C. (1999). The 21 Indispenable Qualities of a Leader. Tennessee: Tomas Nelson Publishers.

[27] McGregor, D. (1960). The Human Side of Enterprise. New York: McGraw Hill.

[28] Morrison, J. G., Kelly, R. T., Moore, R. A., \& Hutchins, S. G. (1997).Tactical decision making under stress (TADMUS) decision support system. Paper presented at the IRIS National Symposium on Sensor and Data Fusion. Retrieved on August 21, 2006, from http://www.pacific-science. com/Images/TADMUS_DSS.pdf

\section{AUTHOR'S BIOGRAPHY}

Abdifatah Omar Ga'al, $(\mathrm{PhD})$ in Business Administration. 15 years ${ }^{\text {ee }}$ experience of teaching and lecturing at institutes and universities. Deputy Rector at Horseed International University (HIU)

Citation: Abdifatah Omar Ga'al, "The Impact of Leadership Style on Employee Performance in Higher Education Institution in Somalia: A Case of Mogadishu City "International Journal of Managerial Studies and Research (IJMSR), vol 8, no. 6, 2020, pp. 26-33. doi: http:// dx.doi.org/10.20431/2349-0349.0806003.

Copyright: (C) 2020 Authors. This is an open-access article distributed under the terms of the Creative Commons Attribution License, which permits unrestricted use, distribution, and reproduction in any medium, provided the original author and source are credited. 